\title{
El glifosato y la democratización del conocimiento para el ejercicio de la "salud colectiva"
}

\author{
Glyphosate and the democratization of knowledge \\ for the exercise of "collective health"
}

No puedo disimular la satisfacción que me produce el haber sido invitada por Salud Colectiva, la revista de la Universidad de Lanús que, haciendo honor a su historia, encara con altura un tema de enorme trascendencia social y política. Precisamente mi vínculo con "Lanús" se remonta a su mítico Policlínico, en particular, con el grupo de Salud Mental que hizo aportes sustantivos en su campo e instaló una práctica de atención comunitaria y "salud para todos".

Por otra parte, para mí es especialmente satisfactorio continuar la línea que abrió Andrés Carrasco, amigo y profesional entrañable, el modelo de científico que necesitamos para impulsar una ciencia y una salud diferentes, en las que seamos todos protagonistas: la gente común, los profesionales y los miembros de una comunidad científico-tecnológica que apueste a compartir el conocimiento, a su democratización y enriquecimiento a través de una relación igualitaria que nos incluya a todos como ciudadanos.

Cuando hablamos de democratización del conocimiento nos estamos refiriendo al proceso que entendemos se hace imperativo impulsar en la sociedad actual -fuertemente condicionada por el fenómeno científico-tecnológico- para el desarrollo de la capacidad de interacción, negociación y participación democrática del conjunto de los ciudadanos. Esto requiere, sin duda, alcanzar un manejo aceptable de ciertos conocimientos fácticos en ciencia y tecnología; pero, a la vez y paralelamente, requiere asegurar el desarrollo de la capacidad de desplegar un pensamiento riguroso y crítico; de formular preguntas pertinentes y reconocer las respuestas fundadas, dando un paso irrenunciable para que se pueda volver a asociar a la ciencia con la razón, contra el oscurantismo; con la libertad, contra la opresión. La opresión que significa la aceptación resignada del juicio inapelable de los que saben.

Con relación a este propósito interesa referirse a esa cara de la producción de la ciencia que se vincula con su responsabilidad respecto a lo que llamamos la democratización de ese conocimiento, que no significa pensar ingenuamente en la posibilidad de multiplicar los expertos: una responsabilidad que debe estar asociada al propio proceso de investigación y concebirse, desde el origen, como uno de los ejes de una política para la ciencia.

¿Por qué? Dado que la ciencia y la tecnología científica modifican, transforman y condicionan profundamente la sociedad, debe entenderse que les cabe a quienes están involucrados en la producción de ese conocimiento la responsabilidad ineludible de contribuir a hacerlo accesible. Lo cual, por otra parte, no es un tema menor y sobre todo para la universidad argentina, en cuyo ámbito tiene lugar la mayor parte de la investigación académica que se hace en el país. 
Para que una ciencia -y esto es válido para la educación también- alcance identidad y valor social, la relación con su comunidad, con su sociedad, debe constituir un eje central para fijar sus objetivos, condicionar su carácter y su temática (lo cual no significa una novedad en los países desarrollados, donde se dictan las reglas del buen hacer en ciencia: la ciencia que se hace en EE.UU. o Francia, por dar un ejemplo, sus políticas de ciencia y técnica, no hay duda alguna que atienden a las necesidades, a las prioridades, de su sociedad).

Nos lo advierten incluso los indicadores de producción científica que, aunque algunos los interpretan como un progreso porque figuramos en los temas de frontera, son vistos de manera diferente por la estudiosa brasileña Lea Velho. Ella muestra, en un trabajo exhaustivamente documentado, que América Latina es insignificante en la "big science" y que, al mismo tiempo, ha perdido espacio en campos ligados a nuestra cultura, a nuestras enfermedades y necesidades, en los que despertábamos fuerte interés porque se estaba aportando en terrenos poco frecuentados. Se ha retrocedido en peso y prestigio en los trabajos descriptivos del medio natural; se ha debilitado nuestra escuela de clínica médica, que tuvo reconocimiento internacional. La fisiología y la bioquímica han cedido lugar a la física teórica y a la biología molecular.

Todo lo anterior puede parecer una digresión apartada de nuestro centro de interés: la democratización del conocimiento. Pero justamente creemos que no es así, ya que en nuestra opinión estas cuestiones no pertenecen exclusivamente al territorio de la ciencia. Son determinaciones del ámbito de las políticas y comprometen a todos los ciudadanos. Tiene que ver, por ejemplo, con la medicina que tenemos, y de la que hemos de ser objeto: si será preventiva o dependiente de los negocios de los laboratorios medicinales. También tiene que ver con la educación que se ha de trasmitir desde la escuela, cómo y cuánto de contenidos, cuánto de desarrollo de la capacidad crítica.

Se trata, entonces, de enfrentar una manifestación más del "pensamiento único", que aparece como el legítimo, colocando a la relación ciencia-sociedad en el centro de una política científica, y a la ciencia-educación/divulgación como uno de los ejes constructores de esa relación, atendiendo a una demanda social que entendemos se debe ayudar a expresar, a sabiendas de que el perfil científico-técnico de la sociedad actual impregna los aspectos más básicos y sutiles de nuestra realidad inmediata como la salud, el ambiente, la producción y el trabajo, por nombrar algunos de los más visibles. De tal forma que sería imperativo asumir que la gente está preparada para dialogar con esa realidad o de lo contrario se convierte en rehén de la misma. Planteado en estos términos, se pretende que la envergadura de la tarea misma consolide el compromiso y la identidad de una comunidad que, al menos en nuestro medio, se ha ido alejando de objetivos de largo aliento empujada, en parte, por sucesivas derrotas.

No ignoramos, a la vez, que una propuesta como esta, para ser algo más que una buena idea, requiere cambios institucionales que den el marco a una renovación cultural en nuestras universidades, a partir de la decisión de priorizar aquello que aporte al desarrollo de una sociedad educada e igualitaria, enfrentando la constitución de castas poseedoras del saber y del poder. Esto requiere criterios diferentes de evaluación y de fijación de objetivos, así como el desarrollo de nuevos campos de investigación, de reflexión y de prácticas educativas; exige un estímulo diferencial que respalde y legitime la creación de publicaciones regionales, que se constituyan en vehículo de promoción de un conocimiento medido con parámetros de calidad y pertinencia apropiados, permitiendo desprenderse de criterios que se aceptan como universales. Todo esto constituye una pesada agenda, que solo adquiere sentido si ha de ser compartida. 
Estamos convencidos de que es el tipo de tarea de enorme complejidad que en nuestra región solo puede hacerse, casi excluyentemente, desde la universidad y, a la vez, solo será viable en el marco de un proceso de integración, considerando a la universidad como vértice intelectual de una sociedad periférica a la que le cuesta encontrar su rumbo frente a tanto embate eficientista y globalizador. Para lo cual la universidad debe retomar un destino que supere al de la formación profesional o la resolución de los problemas de la innovación productiva; cuestiones que no son menores, pero que solo adquirirán su sentido en el marco de un proyecto más grande, como nos señalara la Reforma Universitaria del año 1918 en la Argentina, que sigue constituyendo un legado para la región que es imperativo multiplicar, interpretando las demandas de la sociedad actual.

No quiero terminar sin rendir homenaje a unas "Madres", las de Ituzaingó, que hicieron un ejercicio personal de "democratización del conocimiento". Recogieron una experiencia histórica que nos enorgullece, se calzaron pañuelos blancos y salieron a denunciar los efectos de la fumigación -que ellas advirtieron sin otras herramientas que la sabiduría que nace del dolor y la intuición-, con el apoyo de los médicos de los pueblos del lugar, que más tarde promovieron una convocatoria por parte de la Universidad de Córdoba. Todos juntos enfrentaron una academia ajena y dieron legitimidad a la comunicación científica de Andrés Carrasco, antes que la revista especializada que recibe financiamiento de Monsanto, la publicara.

Rietti, Sara

Doctora en Química. Docente, Maestría en Política y Gestión de la Ciencia y la Tecnología, Universidad de Buenos Aires. Doctora Honoris Causa, Universidad Nacional de Rosario. Miembro del Grupo Fénix, Argentina. srietti@fibertel.com.ar

\section{FORMA DE CITAR}

Rietti S. El glifosato y la democratización del conocimiento para el ejercicio de la "salud colectiva". [Editorial]. Salud Colectiva. 2011;7(3):281-283. 